\title{
Human Sperm Competition: A Comparative Evolutionary Analysis
}

\author{
Michael N. Pham ${ }^{1 *}$ and Todd K. Shackelford ${ }^{1}$
}

${ }^{1}$ Oakland University

*Corresponding author (Email: mnpham@ oakland.edu)

Citation - Pham, M. N., \& Shackelford, T. K. (2014). Human sperm competition: A comparative evolutionary analysis. Animal Behavior and Cognition, 1(3), 410-422. doi: 10.12966/abc.08.13.2014

\begin{abstract}
Sperm competition occurs when a female copulates with two or more males within a sufficiently brief time period, resulting in sperm of the different males competing to fertilize ova. Sperm competition has been documented or inferred to occur across several species. We address the evidence for sperm competition in humans by reviewing literature indicating apparently convergent adaptations to sperm competition in humans and nonhumans. We discuss future research directions, and conclude that the evidence for anatomical, biological, physiological, and behavioral adaptations to human sperm competition provides compelling evidence that sperm competition has been a recurrent feature of human evolutionary history.
\end{abstract}

Keywords - Sperm competition, Humans, Comparative psychology, Evolutionary psychology, Comparative evolutionary psychology

Sperm competition occurs when a female copulates with two or more males within a sufficiently brief time period, resulting in sperm of the different males competing to fertilize ova (Parker, 1970). Among socially monogamous species - animals that form long-term pair bonds and occasionally pursue extra-pair copulations (EPCs) - sperm competition most commonly occurs when females pursue EPCs (Smith, 1984). A paternally investing male whose regular partner pursues EPCs is at risk of cuckoldryunwitting investment of resources into offspring to whom he is genetically unrelated. The costs of cuckoldry may have driven the evolution of male sperm competition tactics - strategic adjustments in psychology, behavior, and physiology that increase sperm competition success. Because males have finite resources for survival and reproduction, males judiciously deploy sperm competition tactics: Males attend to specific sperm competition cues and adjust accordingly their sperm competition tactics.

\section{Do humans have an evolutionary history of sperm competition?}

Cuckoldry is likely to have recurred over human evolution. Current estimates document non-zero rates of discrepant social and genetic fatherhood (Anderson, 2006; Bellis, Hughes, Hughes, \& Ashton, 2005; Wolf, Musch, Enczmann, \& Fischer, 2012). A meta-analysis of 32 published studies documented that $3.1 \%$ of children are genetically unrelated to their social father (Voracek, Haubner, \& Fisher, 2008). Anderson (2006) showed that that $29.8 \%$ of men with low paternity confidence (e.g., those disputing paternity), compared to $1.7 \%$ of men with high paternity confidence, are genetically unrelated to their child. These results suggest that men's perceived cuckoldry risk may reasonably predict their actual cuckoldry risk.

Male sexual jealousy provides evidence that cuckoldry recurred over human evolution. Jealousy 
motivates men to minimize the risk of their partner's EPCs, and jealousy is so strong, in fact, that it is a leading cause of partner-killing across cultures (Buss, 2006; Daly \& Wilson, 1988). Male sexual jealousy could not have evolved without the evolutionary recurrence of cuckoldry (Buss, 2013).

\section{Double-mating}

Human sperm competition occurs when a woman "double-mates" or copulates with two or more men within about five days (sperm remain alive in the female reproductive tract for about five days; Baker \& Bellis, 1995). Using data collected from a nationwide survey of British women, Baker and Bellis (1995) reported the percentage of women who ever double-mated as a function of their sexual experience, operationalized as lifetime number of copulations. For women reporting fewer than 50 lifetime copulations, $17.5 \%$ reported having double-mated at least once. This percentage increases steeply with sexual experience: $71.8 \%$ of women reporting more than 1,000 lifetime copulations reported doublemating at least once. Gallup, Burch, and Berens Mitchell (2006) found that $13.4 \%$ of a sample of American college women copulated with two men within a 24-hour period at least once, and $8.3 \%$ copulated with two men simultaneously at least once.

The temporal window for human sperm competition may extend beyond the temporal window for sperm viability. For example, dead sperm may block cervical pathways for sperm of subsequent ejaculates (Baker \& Bellis, 1995). Additionally, research has yet to investigate the extent to which nonsperm substances in semen (e.g., spermicidals; Baker \& Bellis, 1995) might influence the outcome of human sperm competition or the duration that these substances remain potent in the female reproductive tract. For example, seminal fluid in the female reproductive tract may trigger ovulation (reviewed in Burch \& Gallup, 2006; Gallup, Burch, \& Petricone, 2012).

Additionally, ancestral women's double-mating must sometimes have occurred such that competing sperm were present during periods of conception risk. Indirect evidence corroborates this premise: Modern women are more likely to pursue EPCs during peak fertility (Gangestad, Thornhill, \& Garver-Apgar, 2005; Pillsworth \& Haselton, 2006), in-pair copulation (IPC) frequency remains largely uniform across each fertility cycle (except during menses, when IPC frequency decreases precipitously; reviewed in Brewis \& Meyer, 2005), and men pursue IPCs at a frequency which "tops up" their in-pair partner's reproductive tract with a continuous population of viable sperm (Baker \& Bellis, 1993a).

\section{Relative testis size}

Relative testis size - the ratio of testis weight to body weight - is a reliable proxy both for sperm count and for sperm competition level: A species' level of sperm competition typically correlates with its relative testis size (reviewed in Simmons \& Fitzpatrick, 2012). Additionally, experimentally increasing sperm competition level also increases relative testis size (and, therefore, sperm count; Hosken \& Ward, 2001). Although relative testis size in humans is smaller than in highly polyandrous primates, it is larger than in relatively monogamous primates (Short, 1981), indicating that sperm competition may have occurred over human evolution.

\section{Ejaculate adjustment}

Sperm are "tickets" for the "lottery prize" of fertilizing ova (Parker, 1970; Wedell, Gage, \& Parker, 2002). Males at greater sperm competition risk ejaculate more sperm to increase the probability that their sperm-and not rival sperm-fertilize ova (Wedell et al., 2002). For example, among many avian species, males at greater sperm competition risk ejaculate more sperm at the next copulation (Nicholls, Burke, \& Birkhead, 2001; Pizzari, Cornwallis, Løvlie, Jakobsson, \& Birkhead, 2003). Human males at greater "objective" sperm competition risk - the proportion of time they spend apart from their regular partner since their last IPC - ejaculate more sperm at their next IPC (Baker \& Bellis, 1993a). Males also may adjust other semen parameters in response to sperm competition risk. Human males 
produce masturbatory ejaculates containing a greater percentage of motile sperm when viewing malemale-female ("MMF") pornography (i.e., indexing sperm competition), than when viewing femalefemale-female ("FFF") pornography (i.e., indexing the absence of sperm competition; Kilgallon \& Simmons, 2005).

Whether humans can adjust their ejaculate in a manner predicted by sperm competition theory remains debated. For example, critics have cited the decline in semen quality during recent decades as evidence against the existence of human sperm competition (e.g., Auger, Kunstmann, Czyglik, \& Jouannet, 1995; Bostofte, Serup, \& Rebbe, 1982). Future research should employ experimental methodologies (e.g., priming thoughts of partner infidelity) using large samples to assess ejaculate adjustment.

\section{IPC interest}

Males may possess a sperm competition psychology - a set of information-processing mechanisms that motivate males to judiciously deploy sperm competition tactics. These mechanisms are activated when males perceive sperm competition cues (e.g., female attractiveness: Cornwallis \& O'Connor, 2009; presence of rival males: Nicholls et al., 2001), and produce outputs that motivate them to deploy sperm competition tactics (Goetz, Shackelford, Platek, Starratt, \& McKibbin, 2007).

Among many non-human species, males attend to the presence of sexual rivals and adjust accordingly their sperm competition tactics (Candolin \& Reynolds, 2002; Gage \& Barnard, 1996; Nicholls et al., 2001). Human males at greater objective sperm competition risk report greater IPC interest, and greater distress (e.g., anger, upset, frustration, and persistence) if their regular partner denies their IPC request (Shackelford et al., 2002, 2007), but only among men who perceive that she spends more time with male friends (i.e., potential sexual rivals; Pham \& Shackelford, 2013a). Men assess greater sperm competition risk from their regular partner's absence because it is during her absence that they cannot account for her sexual behavior with other men. Additionally, men experimentally primed with thoughts of partner infidelity reported distress if their regular partner denies their IPC request (Starratt, McKibbin, \& Shackelford, 2013). These studies suggest a male sperm competition psychology that regulates IPC interest according to sperm competition risk.

\section{Forced IPC}

Males at greater sperm competition risk may perform forced IPCs to submit their spermsometimes forcefully - into competition with rival sperm that may be, or will be, in her reproductive tract. Human females whose regular partner is unattractive report lower IPC interest and greater EPC interest during periods of conception risk (Gangestad et al., 2005). Thus, forced IPCs may be a sperm competition tactic that results from sexual conflict - when male mating strategies and female mating strategies are at odds (Shackelford \& Goetz, 2012).

Among socially monogamous avian species, forced IPCs occur predictably (and immediately) following events that index cuckoldry risk (e.g., intrusion of rival males, female absence, partnerobserved female EPCs; Barash, 1997; Cheng, Burns, \& McKinney, 1983; reviewed in Goetz \& Shackelford, 2006). Human males who perform a forced IPC also are more likely to accuse their regular partner of EPCs around the time they perform the forced IPC (Finkelhor \& Yllo, 1985; Russell, 1982). According to both men's reports and women's reports, men who are more sexually coercive toward their regular partner also are more likely to verbally impugn her sexual fidelity (Starratt, Goetz, Shackelford, McKibbin, \& Stewart-Williams, 2008). Among physically abused women, those whose regular partner performed forced IPCs also report that he is more sexually jealous (Frieze, 1983; Gage \& Hutchinson, 2006). Men who report sexually coercing their regular partner also report greater suspicion of her EPC, and women who report a greater likelihood of pursuing EPCs also report that their regular partner is more sexually coercive (Goetz \& Shackelford, 2006; 2009). Among men convicted of physically assaulting their regular partner, those who performed forced IPCs - relative to those who did not perform forced 
IPCs - experienced greater cuckoldry risk events prior to the assault (Camilleri \& Quinsey, 2009). Men at greater objective sperm competition risk are more likely to perform forced IPCs, but only those men who perceive a greater likelihood of their partner's EPC (McKibbin, Starratt, Shackelford, \& Goetz, 2011; reviewed in Goetz, Shackelford, \& Camilleri, 2008).

\section{Frequent IPCs}

Frequent IPC may function as a sperm competition tactic. A male who performs frequent IPCs maintains large numbers of viable sperm in his partner's reproductive tract to increase his chances of success in sperm competition across her fertility cycle. In many avian species, males at greater sperm competition risk perform frequent IPCs. For example, male Montagu harriers (Circus pygagus) experimentally exposed to a rival male-relative to no rival males-performed more frequent IPCs (Mougeot, Arroyo, \& Bretagnolle, 2001). Thus, males may strategically adjust IPC frequency according to sperm competition risk.

In humans, frequent IPCs also may function as a sperm competition tactic. For example, a man performs frequent IPCs if his regular partner is more attractive (Kaighobadi \& Shackelford, 2008), if she has more male friends and male coworkers (i.e., potential sexual rivals; Pham et al., in press), and if he performs more mate guarding behaviors (Shackelford, Goetz, Guta, \& Schmitt, 2006). Additionally, deployment of frequent IPCs as a sperm competition tactic may explain why men (but not women) report continued IPC interest over the duration of a romantic relationship (Klusmann, 2002, 2006).

Frequent IPCs also may function to solve male adaptive problems associated with concealed female fertility status: Human females do not display overt fertility cues. Frequent IPCs may function as a male strategy to maintain large numbers of viable sperm in his partner's reproductive tract across her fertility cycle, ensuring that his sperm are present to fertilize her ova. Although men may detect fertility cues (Haselton \& Gildersleeve, 2011), frequent IPCs minimize the likelihood of missing fertilizations, and also may explain why IPC frequency decreases during menses - a time during which ova cannot be fertilized (reviewed in Brewis \& Meyer, 2005).

\section{Semen displacement}

Among several non-human species, males have adaptations to displace rival semen from a female's reproductive tract. For example, male tree crickets (Truljalia hibinosis) can remove nearly $90 \%$ of a rival's ejaculate from a female's reproductive tract during copulation (Ono, Siva-Jothy, \& Kato, 1989). Humans also may have adaptations for semen displacement. Using artificial human penises, artificial female reproductive tracts, and semen-like fluid, Gallup et al. (2003) provided evidence that the human penis may be able to displace semen from the female reproductive tract during copulatory thrusting. Men perform more semen-displacing copulatory behaviors (e.g., deeper and more thrusts) when they are at a greater recurrent risk of sperm competition (Goetz et al., 2005), and when they accuse their regular partner of infidelity (Gallup et al., 2003). Additionally, men experience post-ejaculatory events that prevent them from displacing their own semen, including decreased copulatory interest with the same woman (reviewed in Gallup \& Burch, 2004), but not with novel women (i.e., Coolidge Effect; O'Donohue \& Plaud, 1991).

Human penile foreskin may affect semen displacement. Circumcised penises have more pronounced coronal ridges - the region where semen collects during copulation - which might afford greater semen displacement (Gallup \& Burch, 2004). Additionally, sperm of one man may "piggyback" under the foreskin of another man's penis (Gallup \& Burch, 2004). If an uncircumcised man (Male A) copulates with a woman (Female A) whom recently copulated with a different man (Male B), then Male A may inadvertently capture underneath his foreskin semen of Male B. Then, if Male A copulates with a different woman (Female B), then Male A may inadvertently deposit semen of Male B into Female B. An unlikely but possible outcome of this phenomenon is that a man impregnates a woman with whom he has never copulated. This hypothesis remains empirically untested. 


\section{Sexual arousal}

Male sexual arousal may proximately cause the deployment of sperm competition tactics. Men's pornography preferences provide insight into male sexual arousal because pornography is produced largely to facilitate or enhance male sexual arousal (Mosher, 1988). Therefore, more sexually arousing pornography is likely more popular and prevalent. Pound (2002) documented that MMF pornography (i.e., indexing sperm competition) is more prevalent than male-female-female (MFF) pornography (i.e., indexing the absence of sperm competition). These findings are consistent with men's reports of their preferences in pornography (Pound, 2002; cf. Hald, 2006). McKibbin, Pham, and Shackelford (2013) found that the frequency of images on adult DVD covers depicting MMF pornography predicted the DVD's sales rank, whereas the frequency of images on adult DVD covers depicting MFF pornography did not predict the DVD's sales rank. Consistent with findings from Pound (2002) and from McKibbin et al. (2013), men produce more competitive ejaculates when viewing MMF pornography than when viewing FFF pornography (Kilgallon \& Simmons, 2005).

An alternative explanation is that men prefer MMF pornography because they are superstimulated by witnessing simultaneous, multiple, sexual acts (e.g., oral sex, vaginal sex). However, Pound (2002) and McKibbin et al. (2013) found that MMF pornography was more arousing than pornography depicting multiple males and multiple females-scenes which likely contained the most frequent representation of simultaneous, multiple, sexual acts. Thus, men likely prefer MMF pornography because of adaptations to sperm competition, and not because of male hypersexuality.

Male sexual arousal causes behavioral and physiological adjustments that may function as sperm competition tactics. For example, men who are more sexually aroused express greater copulatory interest (Ariely \& Loewenstein, 2006) and produce more competitive ejaculates (Zavos, 1985; Zavos \& Goodpasture, 1989). Furthermore, men who are experimentally sexually aroused report a greater likelihood of performing sexually aggressive behaviors (Ariely \& Loewenstein, 2006). Because men are sexually aroused when viewing sperm competition cues, and because their sexual arousal causes deployment of sperm competition tactics, assessing men's sexual arousal provides insight into human sperm competition psychology.

\section{Oral sex}

Here, we define oral sex as oral stimulation of genitals. Individuals report performing oral sex for many reasons. Cornell and Halpern-Felsher (2006) surveyed 425 young men and women who reported that they perform oral sex to retain virginity (because oral sex is sometimes not perceived as "real" sex; Sanders \& Reinisch, 1999), to increase their sexual reputation, to sexually satisfy their partner, and to avoid the risk of pregnancy and diseases associated with penile-vaginal sex. Much evidence suggests a human evolutionary history of oral sex. Oral sex occurs in many cultures (e.g., Guadamuz et al., 2006; Iwawaki \& Wilson, 1983; Lurie, Eugenia, Fernandes, \& Hughes, 1995), including some pre-industrial cultures (Hewlett \& Hewlett, 2010), indicating that oral sex is not a culture-specific practice. Oral sex is depicted frequently in pornography, and pornography appeals to evolved mechanisms: Humans do not possess adaptations to experience sexual arousal in response to viewing computer images, but to viewing "real-life" humans with whom they can copulate (Malamuth, 1996). Oral sex is depicted in ancestral cave paintings (Angulo \& García, 2005). Oral sex occurs across many species (Nishimura, Utsumi, Okano, \& Iritani, 1991; Maruthupandian, \& Marimuthu, 2013; Palagi, Telara, \& Tarli, 2003; Soini, 1987), and behaviors that occur across species indicate the possibility of convergent adaptations. Next, we review how oral sex performed by men on women (cunnilingus) may be related to sperm competition.

Mate retention. Mate retention behaviors reduce the risk of a regular partner's EPC (Buss, 1988; Buss \& Shackelford, 1997). Men may perform cunnilingus on their regular partner to minimize their sperm competition risk by reducing her motivation to pursue EPCs. Women who receive cunnilingus are more sexually satisfied (Richters, de Visser, Rissel, \& Smith, 2006), and women who are more satisfied 
with their regular partner are less likely to pursue EPCs (Santtila et al., 2007). Pham and Shackelford (2013b) found that men who report greater interest in and spend more time performing cunnilingus on their regular partner also report performing more mate retention behaviors.

Infidelity-detection. Men may perform cunnilingus to assess sperm competition risk. Because some semen remains in the reproductive tract following insemination (Baker \& Bellis, 1993b), men may assess their partner's EPC risk by smelling and tasting the presence of rival semen that may be in or near her genitals (Thornhill, 2006). The infidelity-detection hypothesis may explain why men typically perform cunnilingus before (and not after) they ejaculate (Halpern \& Sherman, 1979): Men's own semen might "mask" the odor of rival semen. However, it is possible that men are simply repulsed by their own semen. Indirect evidence indicates that humans can smell the semen of others. For example, fertility clinicians record the odors they smell from semen as part of semen quality analysis (e.g., Mauras, Bell, Snow, \& Winslow, 2005). Pham and Shackelford (2013c) found that men who perceive their regular partner to be more attractive - a sperm competition cue - also report greater interest in and spend more time performing cunnilingus on her.

Fertility detection. Males may perform cunnilingus to assess a female's fertility by sniffing and licking (i.e., oral sex) her genitals to gather scent cues to her fertility status. For example, male cotton-top tamarins (Saguinus Oedipus) that smell a female's scent marks produced at high-fertility-relative to at low-fertility-experience more frequent penile erections and perform more mounting behaviors (Ziegler et al., 1993). Gathering scent cues to fertility status also may explain why males of several non-human species more frequently perform cunnilingus on high-fertility females than on low-fertility females (Dunbar, 1977; Johnston, 1974; Kiddy, Mitchell, Bolt, \& Hawk, 1978; Murphy, 1973; Nishimura et al., 1991; Palagi et al., 2003; Sankar \& Archunan, 2004; Soini, 1987). In humans, men may detect a female's fertility status through scent cues. For example, men rate female genital odors that are produced during high-fertility (relative to low-fertility) as more pleasant smelling (Cerda-Molina, Hernández-López, de la O, Chavira-Ramírez, \& Mondragón-Ceballos, 2013; Doty, Ford, Preti, \& Huggins, 1975).

Sexual arousal. Cunnilingus may be related to male sexual arousal and, therefore, to other sperm competition tactics. Male Indian flying foxes (Pteropus giganteus) that spend more time performing cunnilingus on a female also spend more time copulating with her (Maruthupandian \& Marimuthu, 2013), and Maruthupandian and Marimuthu have interpreted this relationship with respect to sperm competition theory. Males typically perform cunnilingus before they copulate and ejaculate (Halpern \& Sherman, 1979), suggesting that cunnilingus may influence sexual arousal and consequent sperm competition tactics (e.g., copulatory thrusting, ejaculate adjustment). Pham, Shackelford, Welling et al. (2013) found that men who spend more time performing oral sex on their regular partner also spend more time copulating with her, perform more semen-displacing copulatory behaviors, and report greater sexual arousal (e.g., more forceful ejaculation, greater orgasm intensity). Additionally, Cerda-Molina et al. (2013) found that men who smell vaginal odors produced at high-fertility (relative to low-fertility) also experience a surge in testosterone and report greater copulatory interest.

The proposed functions of cunnilingus are not necessarily mutually exclusive. Cerda-Molina et al. (2013) found that men report greater sexual arousal and copulatory interest when smelling vaginal fluids produced at high-fertility relative to low-fertility, supporting both the fertility-detection function and the sexual arousal function of cunnilingus. All of the proposed functions of cunnilingus support the broader hypothesis that cunnilingus minimizes cuckoldry risk for the in-pair male.

Research on the function of oral sex is preliminary, and several directions exist for future research. For example, Pham, Shackelford, Sela, and Welling (2013) provide preliminary evidence that men may perform cunnilingus on their regular partner to promote her orgasm, which may increase the number of sperm she retains in her reproductive tract (Baker \& Bellis, 1993b; reviewed in King \& Belsky, 2012). Because women experience greater satisfaction when receiving cunnilingus (Richters et al., 2006), future research also should explore the reproductive benefits for females. Additionally, oral sex performed by females on males (fellatio) is common in humans, though less common among non-human species. Tan et al. (2009) documented that female short-nosed fruit bats (Cynopterus sphinx) that spend more time performing fellatio on a male also spend more time copulating with him, and Koelman et al. 
(2000) found that a woman is less likely to experience preeclampsia if her regular partner ejaculates into her mouth-and especially if she ingests his semen-prior to conception. We suggest that researchers employ sperm competition theory to guide future work on oral sex.

\section{Remaining issues in human sperm competition}

Male precedence. Male precedence refers to the order in which a male copulates with a femalerelative to other males - and how that order influences sperm competition success. In some species (e.g., Cyrtodiopsis whitei), a male that copulates with a female before rival males copulate with her fertilizes the largest proportion of her ova ("first male precedence"; Lorch, Wilkinson, \& Reillo, 1993). In other species (e.g., Drosophila melanogaster), a male that copulates with a female after rival males copulate with her fertilizes the largest proportion of her ova ("last male precedence"; Wilson, Tubman, Eady, \& Robertson, 1997).

Indirect evidence suggests that human males may exhibit last male precedence (Gallup \& Burch, 2004). For example, men have anatomical (Gallup et al., 2003) and physiological (Gallup \& Burch, 2004) adaptations to displace rival semen-but not their own semen. Additionally, non-sperm substances left in the female reproductive tract from one ejaculate may create a more hospitable environment for subsequent ejaculates (reviewed in Gallup et al., 2012).

The IPC proclivity model proposes that women manipulate the time between their IPCs and their EPCs. Gallup et al. (2006) found that $64.1 \%$ of women delayed indefinitely an IPC following an EPC and suggested that women may be actively avoiding sperm competition. However, if women do not delay an $E P C$ following an IPC, then not only do women actively promote sperm competition, but they also actively ensure that an extra-pair partner secures a competitive advantage associated with last male precedence (e.g., semen displacement). Either possibility (of female avoidance of sperm competition or of female manipulation of male precedence) provides further evidence of an evolutionary history of sperm competition in humans.

Sperm competition intensity. Sperm competition risk refers to the likelihood that a female has copulated or will copulate with two or more males during a given time period. Sperm competition intensity refers to the number of males that a female copulates with during a given time period, and is common in species in which females are highly promiscuous and relatively indiscriminate about with whom they copulate. For example, subdominant red junglefowl (Gallus gallus) males ejaculate the largest number of sperm in the presence of one rival male (i.e., low-intensity sperm competition), a moderate number of sperm when rivals are absent (i.e., zero-intensity sperm competition), and the lowest number of sperm when two or more rivals are present (i.e., high-intensity sperm competition), whereas dominant males ejaculate more sperm as the number of rivals increases (Pizzari et al., 2003).

In humans, contexts of high-intensity sperm competition (e.g., orgies, gang rapes) are less common than the contexts of low-intensity sperm competition (e.g., female EPCs, Smith, 1984). For example, Gallup et al. (2006) found that $3.1 \%$ of college women copulated with three or more men simultaneously at least once. Indirect evidence suggests that men are sensitive to sperm competition intensity. For example, men prefer short-term mating with a woman who has several sexual partners (i.e., high-intensity sperm competition) than with a woman who is in a committed relationship (i.e., lowintensity sperm competition; Shackelford, Goetz, LaMunyon, Quintus, \& Weekes-Shackelford, 2004). Pound (2002) found that men prefer viewing MMF pornography (higher-intensity sperm competition) over male-female (MF) pornography (lower-intensity sperm competition). Because men are "witnessing" a woman copulating with another man, both conditions present an equally high risk of sperm competition, but the two conditions differ in the number of men and, therefore, the intensity of sperm competition. This line of research suggests that sperm competition intensity models in humans mirror sperm competition intensity models in dominant male Gallus gallus (Pizzari et al., 2003): Men facing greater sperm competition intensity may deploy more sperm competition tactics (e.g., produce more competitive ejaculates; experience greater sexual arousal; Kilgallon \& Simmons, 2005; McKibbin et al., 2013; Pound, 2002). 
An evolutionary history of forced copulations by multiple males (i.e., "gang rape") may have generated high-intensity sperm competition. Gang rapes have been documented in several non-human species. For example, in lesser snow geese (Anser caerulescens caerulescens), a female is often gang raped during her regular partner's absence, and her regular partner is absent because he is likely participating in a gang rape of a different female (Mineau \& Cooke, 1979).

Some evidence suggests that rapists more frequently target women at high-fertility than women at low-fertility (Gottschall \& Gottschall, 2003). Women at high-fertility dress more provocatively (Haselton, Mortezaie, Pillsworth, Bleske-Rechek, \& Frederick, 2007) and walk more sexually (Guéguen, 2012), and individuals generally agree on the "ease of rape" when judging the walk of featureless avatars (Gunns, Johnston, \& Hudson, 2002). However, other evidence suggests that women take less sexual risks at highfertility (e.g., Chavanne \& Gallup, 1998).

One-third of rape complaints and one-fifth of confirmed rape cases in the United States are gang rapes (Ullman, 1999). Gang rapes are especially prevalent in certain populations. For example, men in urban townships in the former Transkei region of South Africa invite their male friends to rape a woman, and under many circumstances (e.g., the victim supposedly deserved the rape; the victim did not vocally refuse the rape) this behavior is often legitimized (Wood, 2005). These men may recruit their male friends to forcefully copulate with their regular partner if they suspect or know of her EPCs (Wood, 2005). Among those who serve in the military, 5\% of women report experiencing gang rape during their military service (Sadler, Booth, \& Doebbeling, 2005). There are numerous case studies documenting the occurrence of gang rape perpetrated by college fraternity men (Sanday, 2007). This research suggests that gang rape may be more prevalent under contexts that promote strong male coalitions (e.g., friendships, fraternities, military; Gottschall, 2004).

Gang rape occurs in modern hunter-gatherer tribes, providing further evidence that gang rape may have recurred over human evolutionary history. Gang rape of women by men in the Xingu tribes of South America is so prevalent that the behavior is ritualized (McCallum, 1994). Among the Yanomamo of South America, men gang rape women who are captured from a defeated, neighboring tribe (Sanday, 1981). Gang rape may have been a recurrent context selecting over evolutionary history for adaptations to high-intensity sperm competition in humans.

\section{Conclusion}

In this article, we reviewed evidence that human and many non-human males attend to similar sperm competition cues (e.g., female attractiveness, regular partner's absence, presence and number of rival males) and deploy similar sperm competition tactics (e.g., ejaculate adjustment, forced IPCs, frequent IPCs). In particular, many adaptations to sperm competition in humans have analogs in birds. These cross-species similarities may be a consequence of convergent evolution, because humans and most birds have similar mating systems (i.e., social monogamy) that require solutions to similar adaptive problems (e.g., cuckoldry). The substantial body of research documenting physiological, anatomical, behavioral, and psychological adaptations to sperm competition in birds and many other non-human animals provides evidence that sperm competition was a recurrent feature of the evolutionary histories of these animals. Research on humans also provides evidence that sperm competition was a recurrent feature of human evolutionary history.

\section{References}

Auger, J., Kunstmann, J. M., Czyglik, F., \& Jouannet, P. (1995). Decline in semen quality among fertile men in Paris during the past 20 years. New England Journal of Medicine, 332, 281-285.

Anderson, K. (2006). How well does paternity confidence match actual paternity? Current Anthropology, 47, 513520.

Angulo, J., \& García, M. (2005). Sex in stone: Sexuality, reproduction, and eroticism in the Paleolithic epoch. Madrid: Luzán, 5. 
Ariely, D., \& Loewenstein, G. (2006). The heat of the moment: The effect of sexual arousal on sexual decision making. Journal of Behavioral Decision Making, 19, 87-98.

Baker, R. R., \& Bellis, M. A. (1993a). Human sperm competition: Ejaculate adjustment by males and the function of masturbation. Animal Behaviour, 46, 861-885.

Baker, R. R., \& Bellis, M. A. (1993b). Human sperm competition: Ejaculate manipulation by females and a function for the female orgasm. Animal Behaviour, 46, 887-909.

Baker, R. R., \& Bellis, M. A. (1995). Human sperm competition: Copulation, masturbation and infidelity. London: Chapman \& Hall.

Barash, D. P. (1997). Sociobiology of rape in mallards (Anas platyrhynchos): Response to the mated male. Science, 197, 788-789.

Bellis, M. A., Hughes, K., Hughes, S., \& Ashton, J. R. (2005). Measuring paternal discrepancy and its public health consequences. Journal of Epidemiology and Community Health, 59, 749-754.

Bostofte, E., Serup, J., \& Rebbe, H. (1982). Has the fertility of Danish men declined through the years in terms of semen quality? A comparison of semen qualities between 1952 and 1972. International Journal of Fertility, $28,91-95$.

Brewis, A., \& Meyer, M. (2005). Demographic evidence that human ovulation is undetectable (at least in pair bonds). Current Anthropology, 46, 465-471.

Burch, R. L., \& Gallup, G. G. (2006). The psycho-biology of human semen. In S. M. Platek \& T. K. Shackelford (Eds.), Female infidelity and paternal uncertainty (pp. 141-172). New York: Cambridge University Press.

Buss, D. M. (1988). From vigilance to violence: Tactics of mate retention in American undergraduates. Ethology and Sociobiology, 9, 291-317.

Buss, D. M. (2006). The murderer next door: Why the mind is designed to kill. New York: Penguin.

Buss, D. M. (2013). Sexual jealousy. Psychological Topics, 22, 155-182.

Buss, D. M., \& Shackelford, T. K. (1997). From vigilance to violence: Mate retention tactics in married couples. Journal of Personality and Social Psychology, 72, 346-361.

Camilleri, J. A., \& Quinsey, V. L. (2009). Testing the cuckoldry risk hypothesis of partner sexual coercion in community and forensic samples. Evolutionary Psychology, 7, 64-178.

Candolin, U., \& Reynolds, J. D. (2002). Adjustments of ejaculation rates in response to risk of sperm competition in a fish, the bitterling (Rhodeus sericeus). Proceedings of the Royal Society of London, Series B: Biological Sciences, 269, 1549-1553.

Cerda-Molina, A. L., Hernández-López, L., de la O, C. E., Chavira-Ramírez, R., \& Mondragón-Ceballos, R. (2013). Changes in men's salivary testosterone and cortisol levels, and in sexual desire after smelling female axillary and vulvar scents. Frontiers in Endocrinology, 4, 1-9.

Chavanne, T. J., \& Gallup, G. G., Jr. (1998). Variation in risk taking behavior among female college students as a function of the menstrual cycle. Evolution and Human Behavior, 19, 27-31.

Cheng, K. M., Burns, J. T., \& McKinney, F. (1983). Forced copulation in captive mallards III. Sperm competition. The Auk, 100, 302-310.

Cornell, J. L., \& Halpern-Felsher, B. L. (2006). Adolescents tell us why teens have oral sex. Journal of Adolescent Health, 38, 299-301.

Cornwallis, C. K., \& O'Connor, E. A. (2009). Sperm: Seminal fluid interactions and the adjustment of sperm quality in relation to female attractiveness. Proceedings of the Royal Society B: Biological Sciences, 276, 34673475 .

Daly, M., \& Wilson, M. (1988). Homicide. Hawthorne, NY: Aldine.

Doty, R. L., Ford, M., Preti, G., \& Huggins, G. R. (1975). Changes in the intensity and pleasantness of human vaginal odors during the menstrual cycle. Science, 190, 1316-1318.

Dunbar, I. F. (1977). Olfactory preferences in dogs: the response of male and female beagles to conspecific odors. Behavioral Biology, 20, 471-481.

Finkelhor, D., \& Yllo, K. (1985). License to rape: Sexual abuse of wives. New York: Holt, Rinehart, \& Winston.

Frieze, I. H. (1983). Investigating the causes and consequences of marital rape. Signs, 8, 532-553.

Gage, A. J., \& Hutchinson, P. L. (2006). Power, control, and intimate partner sexual violence in Haiti. Archives of Sexual Behavior, 35, 11-24.

Gage, A. R., \& Barnard, C. J. (1996). Male crickets increase sperm number in relation to competition and female size. Behavioral Ecology and Sociobiology, 38, 349-353.

Gallup, G. G. Jr., \& Burch, R. L. (2004). Semen displacement as a sperm competition strategy in humans. Evolutionary Psychology, 2, 12-23. 
Gallup, G. G., Jr., \& Burch, R. L. (2006). The semen displacement hypothesis: Semen hydraulics and the intra-pair copulation proclivity model of female infidelity. In S. Platek \& T. Shackelford (Eds.), Female infidelity and paternal uncertainty: Evolutionary perspectives on male anti-cuckoldry tactics. Cambridge, UK: Cambridge University Press.

Gallup, G. G., Jr., Burch, R. L., \& Berens Mitchell, T. J. (2006). Semen displacement as a sperm competition strategy: Multiple mating,self-semen displacement, and timing of in-pair copulations. Human Nature, 17, 253-264.

Gallup, G. G. Jr., Burch, R. L., \& Petricone, L. R. (2012). Sexual conflict, infidelity, and vaginal/semen chemistry. In T. K. Shackelford \& A. T. Goetz (Eds.), The Oxford handbook of sexual conflict in humans (pp. 217231). New York: Oxford University Press.

Gallup, G. G. Jr., Burch, R. L., Zappieri, M. L., Parvez, R. A., Stockwell, M. L., \& Davis, J. A. (2003). The human penis as a semen displacement device. Evolution and Human Behavior, 24, 277-289.

Gangestad, S. W., Thornhill, R., \& Garver-Apgar, C. E. (2005). Women's sexual interests across the ovulatory cycle depend on primary partner developmental instability. Proceedings of the Royal Society B: Biological Sciences, 272, 2023-2027.

Goetz, A. T., \& Shackelford, T. K (2006). Sexual coercion and forced in-pair copulation as sperm competition tactics in humans. Human Nature, 17, 265-282.

Goetz, A. T., \& Shackelford, T. K. (2009). Sexual coercion in intimate relationships: A comparative analysis of the effects of women's infidelity and men's dominance and control. Archives of Sexual Behavior, 38, 226-234.

Goetz, A. T., Shackelford, T. K., \& Camilleri, J. A. (2008). Proximate and ultimate explanations are required for a comprehensive understanding of partner rape. Aggression and Violent Behavior, 13, 119-123.

Goetz, A. T., Shackelford, T. K., Platek, S. M., Starratt, V. G., \& McKibbin, W. F. (2007). Sperm competition in humans: Implications for male sexual psychology, physiology, anatomy, and behavior. Annual Review of Sex Research, 18, 1-22.

Goetz, A. T., Shackelford, T. K., Weekes-Shackelford, V. A., Euler, H. A., Hoier, S., Schmitt, D. P., \& LaMunyon, C. W. (2005). Mate retention, semen displacement, and human sperm competition: A preliminary investigation of tactics to prevent and correct female infidelity. Personality and Individual Differences, 38, $749-763$.

Gottschall, J. (2004). Explaining wartime rape. Journal of Sex Research, 41, 129-136.

Gottschall, J. A., \& Gottschall, T. A. (2003). Are per-incident rape-pregnancy rates higher than per-incident consensual pregnancy rates? Human Nature, 14, 1-20.

Guadamuz, T. E., Kunawararak, P., Beyrer, C., Pumpaisanchai, J., Wei, C., \& Celentano, D. D. (2010). HIV prevalence, sexual and behavioral correlates among Shan, Hill tribe, and Thai male sex workers in Northern Thailand. AIDS Care, 22, 597-605.

Guéguen, N. (2012). Gait and menstrual cycle: Ovulating women use sexier gaits and walk slowly ahead of men. Gait and Posture, 35, 621-624.

Gunns, R. E., Johnston, L., \& Hudson, S. M. (2002). Victim selection and kinematics: A point-light investigation of vulnerability to attack. Journal of Nonverbal Behavior, 26, 129-158.

Hald, G. M. (2006). Gender differences in pornography consumption among young heterosexual Danish adults. Archives of Sexual Behavior, 35, 577-585.

Halpern, J., \& Sherman, M. A. (1979). Afterplay: A key intimacy. New York: Pocket Books.

Haselton, M. G., \& Gildersleeve, K. (2011). Can men detect ovulation? Current Directions in Psychological Science, 20, 87-92.

Haselton, M. G., Mortezaie, M., Pillsworth, E. G., Bleske-Rechek, A., \& Frederick, D. A. (2007). Ovulatory shifts in human female ornamentation: Near ovulation, women dress to impress. Hormones and Behavior, 51, 4045.

Hewlett, B. S., \& Hewlett, B. L. (2010). Sex and searching for children among Aka foragers and Ngandu farmers of central Africa. African Study Monographs, 31, 107-125.

Hosken, D. J., \& Ward, P. I. (2001). Experimental evidence for testis size evolution via sperm competition. Ecology Letters, 4, 10-13.

Iwawaki, S., \& Wilson, G. D. (1983). Sex fantasies in Japan. Personality and Individual Differences, 4, 543-545.

Johnston, R. E. (1974). Sexual attraction function of golden hamster vaginal secretion. Behavioral Biology, 12, 111117.

Kaighobadi, F., \& Shackelford, T.K. (2008). Female attractiveness mediates the relationship between in-pair copulation frequency and men's mate retention behaviors. Personality and Individual Differences, 45, 293 295. 
Kiddy, C. A., Mitchell, D. S., Bolt, D. J., \& Hawk, H. W. (1978). Detection of estrus-related odors in cows by trained dogs. Biology of Reproduction, 19, 389-395.

Kilgallon, S. J., \& Simmons, L. W. (2005). Image content influences men's semen quality. Biology Letters, 1, 253255.

King, R., \& Belsky, J. (2012). A typological approach to testing the evolutionary functions of human female orgasm. Archives of Sexual Behavior, 41, 1145-1160.

Klusmann, D. (2002). Sexual motivation and the duration of partnership. Archives of Sexual Behavior, 31, 275-287.

Klusmann, D. (2006). Sperm competition and female procurement of male resources. Human Nature, 17, 283-300.

Koelman, C. A., Coumans, A. B., Nijman, H. W., Doxiadis, I. I., Dekker, G. A., \& Claas, F. H. (2000). Correlation between oral sex and a low incidence of preeclampsia: a role for soluble HLA in seminal fluid? Journal of Reproductive Immunology, 46, 155-166.

Lorch, P. D., Wilkinson, G. S., \& Reillo, P. R. (1993). Copulation duration and sperm precedence in the stalk-eyed fly Cyrtodiopsis whitei (Diptera: Diopsidae). Behavioral Ecology and Sociobiology, 32, 303-311.

Lurie, P., Eugenia, M., Fernandes, L., \& Hughes, V. (1995). Socioeconomic status and risk of HIV-1, syphilis and hepatitis B infection among sex workers in São Paulo State, Brazil. AIDS, 9, 31-37.

Malamuth, N. M. (1996). Sexually explicit media, gender differences, and evolutionary theory. Journal of Communication, 46, 8-31.

Maruthupandian, J., \& Marimuthu, G. (2013). Cunnilingus apparently increases duration of copulation in the Indian flying fox, Pteropus giganteus. PloS ONE, 8, e59743.

Mauras, N., Bell, J., Snow, B. G., \& Winslow, K. L. (2005). Sperm analysis in growth hormone-deficient adolescents previously treated with an aromatase inhibitor: Comparison with normal controls. Fertility and Sterility, 84, 239-242.

McCallum, C. (1994). Ritual and the origin of sexuality in the Alto Xingu. In P. Harvey \& P. Gow (Eds.), Sex and violence: Issues in representation and experience (pp. 90-114). New York: Routledge.

McKibbin, W. F., Pham, M. N., \& Shackelford, T. K. (2013). Human sperm competition in post-industrial ecologies: Sperm competition cues predict pornographic DVD sales rank. Behavioral Ecology, 24, 819823.

McKibbin, W. F., Starratt, V. G., Shackelford, T. K., \& Goetz, A. T. (2011). Perceived risk of female infidelity moderates the relationship between objective risk of female infidelity and sexual coercion in humans (Homo sapiens). Journal of Comparative Psychology, 125, 370-373.

Mineau, P., \& Cooke, F. (1979). Rape in the lesser snow goose. Behaviour, 70, 280-291.

Mougeot, F., Arroyo, B. E., \& Bretagnolle, V. (2001). Decoy presentations as a means to manipulate the risk of extrapair copulation: An experimental study in a semicolonial raptor, the Montagu's harrier (Circus pygargus). Behavioral Ecology, 12, 1-7.

Mosher, D. L. (1988). Pornography defined: Sexual involvement theory, narrative context, and goodness-of-fit. Journal of Psychology and Human Sexuality, 1, 67-85.

Murphy, M. R. (1973). Effects of female hamster vaginal discharge on the behavior of male hamsters. Behavioral Biology, 9, 367-375.

Nicholls, E. H., Burke, T., \& Birkhead, T. R. (2001). Ejaculate allocation by male sand martins, Riparia riparia. Proceedings of the Royal Society of London. Series B: Biological Sciences, 268, 1265-1270.

Nishimura, K., Utsumi, K., Okano, T., \& Iritani, A. (1991). Separation of mounting-inducing pheromones of vaginal mucus from estrual heifers. Journal of Animal Science, 69, 3343-3347.

O'Donohue, W., \& Plaud, J. J. (1991). The long-term habituation of sexual arousal in the human male. Journal of Behavior Therapy and Experimental Psychiatry, 22, 87-96.

Ono, T., Siva-Jothy, M. T., \& Kato, A. (1989). Removal and subsequent ingestion of rivals' semen during copulation in a tree cricket. Physiological Entomology, 14, 195-202.

Palagi, E., Telara, S., \& Tarli, S. B. (2003). Sniffing behavior in Lemur catta: Seasonality, sex, and rank. International Journal of Primatology, 24, 335-350.

Parker, G. G. (1970). Sperm competition and its evolutionary consequences in the insects. Biological Review, 45, 525-567.

Pizzari, T., Cornwallis, C. K., Løvlie, H., Jakobsson, S., \& Birkhead, T. R. (2003). Sophisticated sperm allocation in male fowl. Nature, 426, 70-74.

Pham, M. N., \& Shackelford, T. K. (2013a). The relationship between objective sperm competition risk and men's copulatory interest is moderated by partner's time spent with other men. Human Nature, 24, 476-485.

Pham, M. N., \& Shackelford, T. K. (2013b). Oral sex as mate retention behavior. Personality and Individual Differences, 55, 185-188. 
Pham, M. N., \& Shackelford, T. K. (2013c). Oral sex as infidelity-detection. Personality and Individual Differences, $54,792-795$.

Pham, M. N., Shackelford, T. K., Holden, C. J., Zeigler-Hill, V., Hummel, A., \& Memering, S. L. (in press). Partner attractiveness moderates the relationship between number of sexual rivals and in-pair copulation frequency in humans (Homo sapiens). Journal of Comparative Psychology.

Pham, M. N., Shackelford, T. K., Sela, Y., \& Welling, L. L. M. (2013). Is cunnilingus-assisted orgasm a male sperm-retention strategy? Evolutionary Psychology, 11, 405-414.

Pham, M. N., Shackelford, T. K., Welling, L. L. M., Ehrke, A. D., Sela, Y., \& Goetz, A. T. (2013). Oral sex, semen displacement, and sexual arousal: Testing the ejaculate adjustment hypothesis. Evolutionary Psychology, $11,1130-1139$.

Pillsworth, E. G., \& Haselton, M. G. (2006). Male sexual attractiveness predicts differential ovulatory shifts in female extra-pair attraction and male mate retention. Evolution and Human Behavior, 27, 247-258.

Pound, N. (2002). Male interest in visual cues of sperm competition risk. Evolution and Human Behavior, 23, 443446.

Richters, J., de Visser, R., Rissel, C., \& Smith, A. (2006). Sexual practices at last heterosexual encounter and occurrence of orgasm in a national survey. Journal of Sex Research, 43, 217-226.

Russell, D. E. H. (1982). Rape in marriage. New York: Macmillan Press.

Sadler, A. G., Booth, B. M., \& Doebbeling, B. N. (2005). Gang and multiple rapes during military service: Health consequences and health care. Journal of the American Medical Women's Association, 60, 33-41.

Sanday, P. R. (1981). The socio-cultural context of rape: A cross-cultural study. Journal of Social Issues, 37, 5-27.

Sanday, P. (2007). Fraternity gang rape: Sex, Brotherhood, and Privilege on Campus. New York: NYU Press.

Sanders, S. A., \& Reinisch, J. M. (1999). Would you say you had sex if...?. The Journal of the American Medical Association, 281, 275-277.

Sankar, R., \& Archunan, G. (2004). Flehmen response in bull: Role of vaginal mucus and other body fluids of bovine with special reference to estrus. Behavioural Processes, 67, 81-86.

Santtila, P., Wager, I., Katarina, W., Harlaar, N., Jern, P., Johansson, A., ...Sandnabba, N. K. (2007). Discrepancies between sexual desire and sexual activity: Gender differences and associations with relationship satisfaction. Journal of Sex and Marital Therapy, 34, 29-42.

Shackelford, T. K., \& Goetz, A. T. (Eds.). (2012). The Oxford handbook of sexual conflict in humans. New York: Oxford University Press.

Shackelford, T. K., Goetz, A. T., Guta, F. E., \& Schmitt, D. P. (2006). Mate guarding and frequent in-pair copulation in humans. Human Nature, 17, 239-252.

Shackelford, T. K., Goetz, A. T., LaMunyon, C. W., Quintus, B. J., \& Weekes-Shackelford, V. A. (2004). Sex differences in sexual psychology produce sex similar preferences for a short-term mate. Archives of Sexual Behavior, 33, 405-412.

Shackelford, T. K., Goetz, A. T., McKibbin, W. F., \& Starratt, V. G. (2007). Absence makes the adaptations grow fonder: Proportion of time apart from partner, male sexual psychology, and sperm competition in humans (Homo sapiens). Journal of Comparative Psychology, 121, 214-220.

Shackelford, T. K., LeBlanc, G. J., Weekes-Shackelford, V. A., Bleske-Rechek, A. L., Euler, H. A., \& Hoier, S. (2002). Psychological adaptation to human sperm competition. Evolution and Human Behavior, 23, 123138.

Short, R. V. (1981). Sexual selection in man and the great apes. In C. E. Graham (Ed.), Reproductive biology of the great apes (pp. 319-341). New York: Academic Press.

Simmons, L. W., \& Fitzpatrick, J. L. (2012). Sperm wars and the evolution of male fertility. Reproduction, 144, 519-534.

Smith, R. L. (1984). Human sperm competition. In R. L. Smith (Ed.), Sperm competition and the evolution of animal mating systems (pp. 601-659). New York: Academic Press.

Soini, P. (1987). Sociosexual behavior of a free-ranging Cebuella pygmaea (Callitrichidae, platyrrhini) troop during postpartum estrus of its reproductive female. American Journal of Primatology, 13, 223-230.

Starratt, V. G., Goetz, A. T., Shackelford, T. K., \& Stewart-Williams, S. (2008). Men's partner-directed insults and sexual coercion in intimate relationships. Journal of Family Violence, 23, 315-323.

Starratt, V. G., McKibbin, W. F., \& Shackelford, T. K. (2013). Experimental manipulation of psychological mechanisms responsive to female infidelity. Personality and Individual Differences, 55, 59-62.

Tan, M., Jones, G., Zhu, G., Ye, J., Hong, T., Zhou, S., ...Zhang, L. (2009). Fellatio by fruit bats prolongs copulation time. PloS ONE, 4, e7595. 
Thornhill, R. (2006). Foreward: Human sperm competition and women's dual sexuality. In T. K. Shackelford \& N. Pound (Eds.), Sperm competition in humans: Classic and contemporary readings (v-xix). New York: Springer.

Ullman, S. E. (1999). A comparison of gang and individual rape incidents. Violence and Victims, 14, 123-133.

Voracek, M., Haubner, T., \& Fisher, M. L. (2008). Recent decline in nonpaternity rates: A cross-temporal metaanalysis 1, 2. Psychological reports, 103, 799-811.

Wedell, N., Gage, M. J., \& Parker, G. A. (2002). Sperm competition, male prudence and sperm-limited females. Trends in Ecology and Evolution, 17, 313-320.

Wilson, N., Tubman, S. C., Eady, P. E., \& Robertson, G. W. (1997). Female genotype affects male success in sperm competition. Proceedings of the Royal Society of London. Series B: Biological Sciences, 264, 1491-1495.

Wolf, M., Musch, J., Enczmann, J., \& Fischer, J. (2012). Estimating the prevalence of nonpaternity in Germany. Human Nature, 23, 208-217.

Wood, K. (2005). Contextualising group rape in post-apartheid South Africa. Culture, Health and Sexuality, 7, 303317.

Zavos, P. M. (1985). Seminal parameters of ejaculates collected from oligospermic and normospermic patients via masturbation and at intercourse with the use of a Silastic seminal fluid collection device. Fertility and Sterility, 44, 517-520.

Zavos, P. M., \& Goodpasture, J. C. (1989). Clinical improvements of specific seminal deficiencies via intercourse with a seminal collection device versus masturbation. Fertility and Sterility, 51, 190-193.

Ziegler, T. E., Epple, G., Snowdon, C. T., Porter, T. A., Belcher, A. M., \& Küderling, I. (1993). Detection of the chemical signals of ovulation in the cotton-top tamarin, Saguinus oedipus. Animal Behaviour, 45, 313-322. 